\title{
How Can a Corporate (Compliance) Culture Be Described and Effectively Measured?
}

\author{
Lucie Andreisová \\ Correspondence: Ing. Lucie Andreisová, Ph.D., Department of Business and European Law, Faculty of International \\ Relations, University of Economics in Prague; Nám. W. Churchilla 1938/4, 13067 Prague 3, Czech Republic.
}

Received: July 9, 2018

doi:10.11114/bms.v4i3.3537

\author{
Accepted: August 2, 2018 \\ Online Published: August 14, 2018
}

URL: https://doi.org/10.11114/bms.v4i3.3537

\begin{abstract}
In July 2016, the FRC published a report on corporate culture and the role of boards (see below). This report serves as an important complement to respective provisions of UK Corporate Governance Code - a code which is perceived as a best practice manual for building and maintaining a good level of corporate governance and is therefore adapted by many European lawmakers and regulators. This regulation puts an enhanced emphasis on 'corporate (compliance) culture' as it, among others, states that: 'Boards should devote sufficient resource to evaluating culture and consider how they report on it.' What shall, however, be understood by this term? How can such a term be defined, measured and reported on? The aim of the presented discussion paper is to help answering those theoretical questions, as well as to propose a reliable 'culture measurement tool' which could be effectively used in nowadays business practice.
\end{abstract}

Keywords: compliance program, corporate (compliance) culture, corporate governance

JEL Code(s): K42, L20, M14

\section{Introduction}

In July 2016, the Financial Reporting Council (hereinafter also the 'FRC') published a report on corporate culture and the role of boards (The Financial Reporting Council Limited, 2016). This report serves as an important supplement to respective provisions ${ }^{1}$ of the UK Corporate Governance Code (The Financial Reporting Council Limited, 2016), hereinafter also the 'Code' - a code which is not only perceived as the core (general) regulation for those companies which are listed on London Stock Exchange, but also a kind of best practice for many other (not only) European laws and regulations in the area of corporate governance - including the example of Czech Republic ${ }^{2}$ (i.e. author's domestic jurisdiction).

Even though the UK Corporate Governance Code itself and related guidelines represent a very complex and pretty detailed regulation of all governance, risk and compliance (hereinafter also 'GRC') related areas and issues, it shall be highlighted that this regulation puts an extremely enhanced emphasis on 'corporate (compliance) culture'. But what does this term mean? How can a corporate (compliance) culture be defined, and, more importantly, monitored (evidenced), measured and reported on? The author personally favours for the definition that: 'Culture is what people do when no one is looking.' (Andreisová, 2017). There are, however, many other definitions of corporate (compliance) culture. Bowdler \& Kettle (2017), for example, state that corporate culture can be defined as the overall environment that affects how specific compliance issues are handled. In a strong corporate culture, employees follow the right processes and perform the right controls even without oversight. The authors further add that good internal indicators for measuring the actual level of corporate culture can be: (a) How effective the company is in meeting its compliance regulations and detecting compliance problems? (b) How proactive its employees are in averting various compliance issues? They summarise their thoughts by stating that the desired culture shall be the one where people want to be compliant (Bowdler \& Kettle, 2017).

The most recent trend in global regulatory compliance landscape therefore shows a significant shift towards behavioural compliance, i.e. a special focus on so called conduct regulation. It is important to realise that, generally speaking, there are only two types of breaches. Either people do not do what they are supposed to do, but the internal rules and/or policies etc. meet their purpose; or even though people do what they are supposed to do, their behaviour does not meet the desired outcomes - i.e. the internal rules and/or policies etc. do not meet their purpose (Biegelman, 2008). What does this mean for compliance and other professionals? The author believes that they certainly need to deal 
with both categories - remove any inconsistencies in their internal policy governance systems on one hand, and set up boundaries of acceptable breaches, pay attention to those which are not acceptable for their business operations anymore, and generally achieve a better corporate (compliance) culture on the other hand.

Regulation around culture is always principle-based ${ }^{3}$. It is therefore necessary to create a robust internal system of managing and monitoring corporate (compliance) culture, precisely define and describe its individual elements and focus on documenting (evidencing) any actions taken. Businesses all around the world need to do this not only to maintain a brand of an ethical company, but also to fulfil related GRC responsibilities (such as, for example, those arisen under the above mentioned UK Corporate Governance Code). In other words, it is a matter of fact that the Code and other similar (local) regulations nowadays significantly highlight the role and further involvement of senior management in delivering sustainable success, engagement with employees, customers, shareholders and other stakeholders, and in embedding and assessing the desired corporate (compliance) culture (The Financial Reporting Council Limited, 2016). The below chapter proposes how this can be delivered in practice - through a fictional corporate case study and practical proposal of so called 'Business Integrity Index'.

\section{What Is a Corporate (Compliance) Culture and Why It Matters?}

The recent development in the field of compliance and general ethics ${ }^{4}$ shows that various internal and/or external rules and sanctions clearly have their place, but do not always - on their own - deliver productive behaviours over long-term. A healthy corporate (compliance) culture, on the other hand, both protects and generates value. Therefore, it seems to be a much better idea to have a continuous focus on culture rather than to wait for a crisis (Schenková, 2017). Good corporate (compliance) culture is the enabler, the differentiator and a source of competitive advantage.

In a corporate context, culture can be defined as a combination of values, attitudes and behaviours manifested by a company in its operations and relations with its internal and external stakeholders - i.e. shareholders, employees, customers, suppliers and the wider communities which are affected by its conduct. It is obvious that companies do not live in isolation; in order to prosper, they need to build and maintain successful relationships with a wide split of stakeholders. Such relationships are to be seen as successful and enduring if they are based on values like respect, trust and mutual benefit (Fox, 2012). In addition, the FRC further states that (The Financial Reporting Council Limited, 2016): 'Business' reputation is still recovering from the impact of the global financial crisis and continuing examples of poor corporate behaviour. As we have seen, cultural failures damage reputation and have a substantial impact on shareholder value. Intangible assets such as intellectual property, customer base and brand now account for over 80 per cent of total corporate value, compared to under 20 per cent 40 years ago. This shift magnifies the impact on total value when a reputational crisis occurs.' Culture is much more about people than it is about rules. Codes of ethics or conduct are just a baseline - corporate (compliance) culture is created by what you do rather than what you say. David Tyler, Chairman of the Board of Directors of Sainsbury, once said that (English \& Hammond, 2017): 'What counts is the actual behaviour of the organisation and its top people. This is far more significant than a hundred statements about a company's culture or it's ethical policy.'

It is a matter of fact that in terms of culture the major role is being played by company's senior (executive) management. They have ultimate accountability for corporate (compliance) culture and must exercise respective oversight; they can also - thanks to their roles and visibility in the company - influence culture in many ways (Andreisová, 2017). The key challenge is that the senior (executive) management must understand what in practice drives the behaviour of their employees and lower management and to shape and influence those drivers in a way that will foster greater sustainability and improved performance over time. The alignment and consistency of behaviours of corporate leaders (executive management) and how they communicate through words and actions is seen as an essential cultural aspect (Schenková, 2017).

To sum up, businesses should feel encouraged to find ways to understand and influence the factors which affect their culture and behaviours. National, international and European lawmakers and regulators are supporting these trends by enforcing the above mentioned principle-based conduct regulation. Such an approach keeps the legal framework of corporate governance as flexible as possible, as it influences the individual and corporate behaviour, but does not ultimately control it. For further insight, please see Section 172 of the UK Companies Act $2006^{5}$, as one of the professionally acknowledged examples - internationally recognised reference point.

\section{How Can a Corporate (Compliance) Culture Be Embedded Throughout a Particular Organisation?}

In taking action on culture, all of those who are involved are advised to consider the following three important areas (The Financial Conduct Authority, 2018):

1. Connect purpose and strategy on culture - i.e. the strategy to achieve a company's purpose should reflect the values and culture of the company and should not be developed in isolation. 
2. Align values and incentives - i.e. financial and non-financial incentives should be appropriately balanced and linked to behavioural objectives. Without that, values would be seen as 'nice words on a piece of paper' only. They need to be translated into a set of expected behaviours - preferably those behaviours that are meaningful to the company and those who work there.

3. Assess and measure - i.e. careful thought should be given to how culture is assessed and reported on.

Meanwhile the first two issues are often seen as strategic business areas, the third one can be easily dealt with by any compliance and/or legal practitioner (professional) - as there is a wide range of potential cultural indicators available. Companies can easily choose and monitor those that are appropriate to their business and also the outcomes they see. A practical demonstration (author's proposal) is introduced in the following chapter. At this point, it shall, however, be highlighted, that the author strongly believes that any objective cultural assessment that aims to gain a more detailed practical insight always requires - regardless of what level of automation, digitalization and technology is in place - to interpret the obtained information sensitively, as there is always a number of contextual factors and stories behind the dashboard figures that one must be aware of.

\subsection{Case Study: A Practical Example of Embedding an Ethical Culture}

To take the above recommendations into practice, the author would like to introduce a fictional case study - several cultural efforts of a big multinational company seated in the United Kingdom (hereinafter only the 'Company'). ${ }^{6}$ These will demonstrate how the above introduced FCA's concept can be introduced in a business (corporate) practice - based on author's professional interpretation and personal beliefs.

In response to the above mentioned FRC report, the Company has prepared a board paper which: (a) describes its culture; (b) outlines the ways in which its culture is embedded thorough the whole organisation; (c) details the mechanisms in place to provide insight and feedback on its culture; and (d) summarises potential cultural challenges. The paper has been introduced and further discussed with its Board of Directors - to make sure the Board is properly consulted and also involved in these culture-related topics.

The Company defines its culture through three interconnected elements: (1) Acting in an Ethical Way, i.e. an internal principle that sets out the type of organisation the Company wants to be; (2) Business Principles, i.e. the values that the Company respects; and the (3) Code of Conduct, i.e. the behaviours that the Company expects from any of its stakeholders. Together, these elements set out what the Company expects from all of those who work with and for it, and how the business should be carried out. The Company's culture is linked to its business purpose and strategy. It has evolved over time reflecting its growth, changing consumer behaviour and expectations, shifts in regulatory and legal requirements, and changing attitudes towards the role of large businesses in society. The Company's leaders have a critical role in setting the tone of the organisation and play a key role in championing the expected behaviours. They also take action to address behaviours that fall short of the Company's expectations. In addition, various indicators are used to assess and provide insight into Company's culture. These are being regularly reviewed. Mechanisms are also in place to provide assurance that Company's people act and behave in line with its expectations. These mechanisms include internal policies and plenty of compliance processes and reviews, internal audits and providing formal channels for employees to 'blow the whistle' (i.e. to 'speak up'). This combination provides for valuable insight into Company's culture and, more importantly, highlights where changes and actions are required to better manage risks.

In embedding culture within the organisation, the Company follows an integrated approach. Such an approach incorporates the following cultural elements:

1. Recognise the value of culture - the Company recognises that ethical conduct is just as important as high performance. Failure to operate ethically impacts its business success. In the past, the Company continued to review its policies and develop tools for employees that support the implementation of its principles. They ensure that any concerns can be easily and confidentially raised and investigated. This is part of Company's Doing What's Right approach (communications campaign). The campaign utilises new training techniques such as gamification (designed to enhance learning end employee engagement). Training materials seek to highlight number of common compliance situations, such as dealing with personal data, conflicts of interest and/or accepting gifts. By bringing specific risk situations to life, these materials are increasing awareness and understanding of the issues an individual may face and how to deal with specific situations that could arise.

2. Demonstrate leadership - the Company's leaders are critical to setting the 'tone from the top'. The Company has led several campaigns to reinforce and communicate its values and beliefs. This has included: (a) CEO communications on business integrity and the importance of whistleblowing; (b) the executive management's campaigns on health and safety; (c) the executive management's engagement campaigns on Acting in an Ethical Way (see above) and customer experience. Apart from that, the Company has also held annual events 
for middle managers to ensure the 'tone from the middle' is aligned and consistent. Additional support was also provided to middle managers to enable successful local implementation of policies, processes and tools.

3. Be open and accountable - the Company encourages openness and transparency in business reporting and the way in which it works with internal and external stakeholders. Internally, it has a range of channels and mechanisms in place to listen and engage with employees on corporate strategy, performance, organisational change and employee matters - e.g. engagement with employees through town hall events, employee networks, digital communication platforms etc. Externally, the Company has sought to increase openness and transparency in two areas that are of public interest and concern: (a) taxation and total economic contribution; and (b) supply chain integrity and safety.

4. Embed and integrate - multiple functions and teams in the Company are involved in integrating and embedding culture into its policies, processes and ways of working. Within HR, the Company's policies and processes are aligned to the above mentioned principle of Working in an Ethical Way, including recruitment, induction, training, leadership development, performance management, and succession. Training is tailored across the Company with more support given to high-risk areas, e.g. bribery and corruption.

5. Align values and incentives - the Company rewards people based on their performance, potential and contribution to the overall success. The Company continually reviews how it measures and assesses individual performance and places a great emphasis on developmental conversations between its line (people) managers and employees. Individual performance is assessed both on 'what' has been achieved, and 'how' the activities have been delivered.

6. Measure and assess - the Company's preferred approach in measuring and assessing culture is to use a variety of indicators that can be monitored throughout the year - e.g. monitoring attrition, employee engagement, health \& safety and wellbeing measures etc. In addition to these cultural indicators, three core mechanisms are in place to test and assess the health of Company's culture: (1) Policy Compliance Review process; (2) Internal Audit; and (3) Whistleblowing.

7. Exercise stewardship - a key element of Company's stewardship is its approach to managing risks. The Company has a clear framework for identifying and managing risks, both at an operational and strategic level. The Company's global Risk Management Framework is designed to identify risks, set risk appetite, put in place appropriate measures to ensure all identified risks are properly monitored and managed, and facilitate informed decision making.

\section{Is There an Effective Way How to Measure the Level of Corporate (Compliance) Culture and Report on It?}

Senior management teams often struggle to understand the forces that drive behaviour in their businesses. Most of them agree that culture cannot be easily measured. However, they do have access to a wide range of culture-related data and information that might shed light on the drivers of behaviour within their organisations and help them to shape it (Montagnon, 2018).

To strengthen and improve the monitoring activities and general senior management's involvement in the area of corporate (compliance) culture, the author suggests that businesses focus on collecting and comparing various cultural indicators that provide sufficient and reliable insight into their internal cultures. A practical example is suggested below - a so called Business Integrity Index ${ }^{7}$; a cultural dashboard consisting of core data from across various high-risk policy areas and other significant categories - such as internal audit results, health and safety measures, financial risk and financial controls metrics (i.e. financial operations data), technology security data (e.g. technology security incidents), internal investigations and whistleblowing figures, gifts and hospitality, conflicts of interest, results from compliance reviews - incl. deep dives and remedial action plans, employee surveys, training completion rates, employee churn (including dismissals), social media records, supply chain management data, regulatory fines and breaches, customer satisfaction data (e.g. Net Promoter Score, customer survey data and customer complaints) etc. With the use of both - data and trend analysis (as both qualitative and also quantitative data are needed), this approach enables the concerned audience to periodically review and effectively overview the current global and/or local trends, to verify various cultural correlations and hypothesis, to better understand potential local cultural specifics, and also to rank the individual business operations and entities based on internal and/or external indexing (in case of global business structures).

As highlighted above, a proper data interpretation is seen as crucial - as a simple look at the collected data will never take the senior management through the whole story and will never allow them to properly understand the drivers behind such results. 


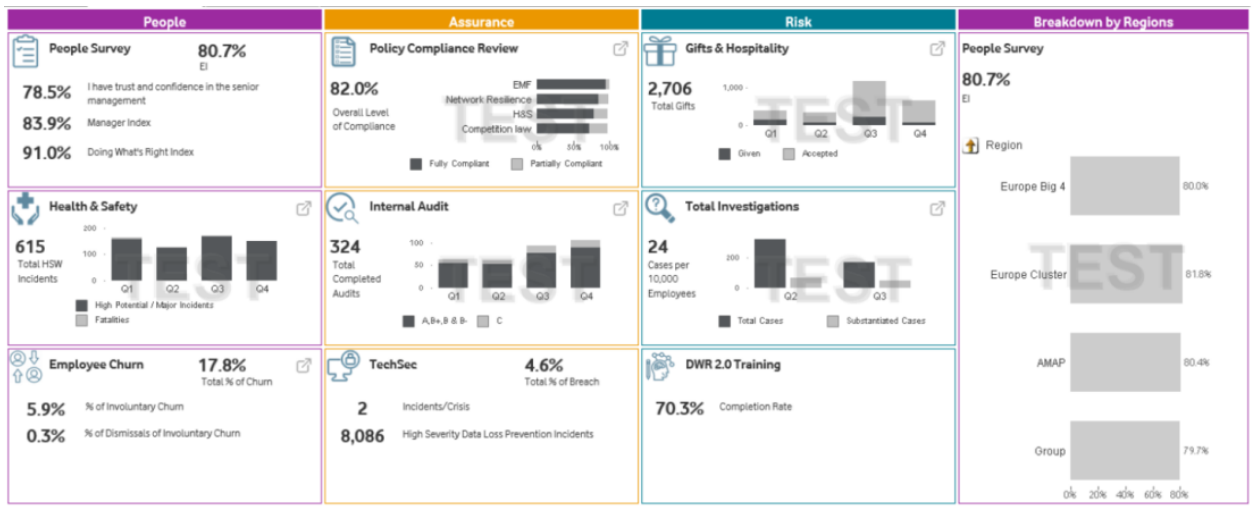

Figure 1. Proposal of the 'Business Integrity Index' - overview and structure of the above discussed culture-related KPIs (source: created by the author)

A great overview of recommended key performance (cultural) indicators and related thoughts, recommendations and further explanations are listed in IBE's paper on culture, i.e. Montagnon, P. Culture Indicators: Understanding corporate behaviour. London: Institute of Business Ethics, 2018. 49 p. ISBN 978-1-908534-34-7. Based on a survey introduced in this paper, the most common indicators used for measuring culture in the UK business environment are whistleblowing data, diversity, employee surveys, regulatory infringements, health and safety records etc. Apart from that, the paper represents a high-quality insight into several related sub-topics, such as external reporting on culture, reporting frequency, current challenges for the UK boards etc.

\section{Conclusion and Discussion}

Corporate (compliance) culture has become a big talking point for plenty of businesses. This might be a reflection of related legal and/or regulatory requirements (see above), but also a response to plenty of culture-based researches and studies which highlight the impact of good (healthy) corporate culture on business performance (see above). Culture is understood as a combination of factors that define the way people within a particular organisation behave. It starts with a clear set of corporate values and an understanding of the purpose of each entity. This further leads on to development of framework in which those values are built into the way the company and its staff operate on a day-to-day basis (Montagnon, 2018). Embedding the culture throughout a particular organisation is principally the job of senior (executive) management - as these management teams play a vital role in setting the values, in overseeing the embedding process and in assuring themselves that the resulting culture is the one they really want. This is, with no doubts, a significant new challenge for them. The way how this theory can be taken into practice has been demonstrated in the above presented fictional case study - as proposed by the author herself as part of this general discussion paper.

Challenges also remain when companies are asked to measure culture. They often start with stating their internal values. It is, however, important to realise that these values are only half of the story. When it comes to everyday practice, the real behaviours and also the reasons behind those are what is counted. Some companies are starting to use new and innovative ways of measuring culture - which is also what the author proposes in the last chapter, through creating a 'Business Integrity Index' - a practical tool summarizing the required cultural KPIs and providing the senior management and compliance (as well as other) professionals with necessary culture overview. The majority of those are, however, only starting this long-term journey - as defining, measuring and embedding culture certainly requires time. As the author underpins above, employee surveys are the most common default measure for a variety of international companies - similarly health and safety statistics, diversity and inclusion metrics, customer satisfaction data, staff recruitment and churn rates etc. - but it is important to realise that each of these metrics has only a limited story to tell, which is why a careful and sensitive data analysis and interpretation is always seen as crucial. Turning the intangible into something tangible is not an easy task and the output of these efforts could very easily become misleading.

\section{Acknowledgement(s)}

This discussion paper has been supported by Internal Grant Agency of the University of Economics in Prague, F2/22/2017 (IG207017).

\section{References}

Act No. 418/2011 Coll., on Criminal Liability of Legal Entities, as amended.

Act No. 89/2012 Coll., Civil Code, as amended.

Act No. 90/2012 Coll., on Business Companies and Cooperatives (Business Corporations Act), as amended. 
Andreisová, L. (2016). Building and Maintaining an Effective Compliance Program. Istanbul: International Journal of Organizational Leadership, 5.

Andreisová, L. (2017). Duty of Care of Members of Statutory Bodies in Capital Business Companies and its Relation to Internal Compliance Programs (dissertation). Prague: University of Economics, Faculty of International Relations, Department of Business and European Law.

Biegelman, M. T. (2008). Building a world-class compliance program: Best practices and strategies for success. John Wiley \& Sons. https://doi.org/10.1002/9781118268193

Bowdler, J., Kettle, R., \& Coll. (2017). Diploma in Governance, Risk and Compliance: Course Manual. Birmingham: International Compliance Training Ltd.

English, S., \& Hammond, S. (2014). Cost of Compliance 2014. Thomson Reuters Accelus.

Fox, T. (2012). Lessons Learned on Compliance and Ethics: The Best from the FCPA Compliance and Ethics Blog. Ethics 360 Media.

Montagnon, P. (2018). Culture Indicators: Understanding corporate behaviour. London: Institute of Business Ethics.

Schenková, K., Lasák, J., \& Coll. (2017). Compliance in business practice. Prague: C. H. Beck.

The Financial Conduct Authority. DP18/2: Transforming culture in financial services. London, 2018. Available online: $<$ https://www.fca.org.uk/publications/discussion-papers/dp18-2-transforming-culture-financial-services>.

The Financial Reporting Council Limited. Corporate Culture and the Role of Boards. Report of Observations. London, 2016. Available

online:

<https://www.frc.org.uk/getattachment/3851b9c5-92d3-4695-aeb2-87c9052dc8c1/Corporate-Culture-and-the-Role -of-Boards-Report-of-Observations.pdf $>$.

The Financial Reporting Council Limited. The UK Corporate Governance Code. London, 2016. Available online: <https://www.frc.org.uk/Our-Work/Codes-Standards/Corporate-governance/UK-Corporate-Governance-Code.aspx>.

UK Companies Act 2006.

\section{Notes}

Note 1. Example provision: 'One of the key roles for the board includes establishing the culture, values and ethics of the company. The directors should lead by example and ensure that good standards of behaviour permeate throughout all levels of the organisation. This will help prevent misconduct, unethical practices and support the delivery of long-term success.'

Note 2. See, for example, the new Act No. 89/2012 Coll., Civil Code, Act No. 90/2012 Coll., on Business Companies and Cooperatives (Business Corporations Act), or Act No. 418/2011 Coll., on Criminal Liability of Legal Entities.

Note 3. The main reason for the above is that there is no 'one-size-fits-all' when it comes to culture.

Note 4. See, for example, Montagnon, P. Culture Indicators: Understanding corporate behaviour. London: Institute of Business Ethics, 2018.

Note 5. Section 172, UK Companies Act 2006: (1) A director of the company must act in the way he considers, in good faith, would be most likely to promote the success of the company for the benefit of its members as a whole, and in doing so have regard (amongst other matters) to - (a) the likely consequences of any decision in the long-term; (b) the interests of the company's employees; (c) the need to foster the company's business relationships with suppliers, customers and others; (d) the impact of the company's business relationships with suppliers, customers and others; (e) the desirability of the company maintaining a reputation for high standards of business conduct, and $(f)$ the need to act fairly as between members of the company.

Note 6. Please note that this is a fictional case study only - drafted by the author herself to introduce and explain the above mentioned principles in practice. The case study has been inspired by training sessions and workshops at ICT (ICA) in London, 2018.

Note 7. Please note that this is a fictional name only - proposed by the author herself to demonstrate the current theoretical concepts.

\section{Copyrights}

Copyright for this article is retained by the author(s), with first publication rights granted to the journal.

This is an open-access article distributed under the terms and conditions of the Creative Commons Attribution license which permits unrestricted use, distribution, and reproduction in any medium, provided the original work is properly cited. 